\title{
Strengthening of masonry rings with composite materials
}

\author{
Jerzy Jasieńko, Krzysztof Raszczuk, Piotr Frąckiewicz* 피, Kajetan Kleszcz and Łukasz Bednarz
}

\begin{abstract}
The paper presents the results of experimental testing of six masonry rings built to technical scale and strengthened with CFRP strips and sheets and also with an FRCM system with PBO, glass, basalt and carbon fibers. The rings were subjected to tensile loads induced by four hydraulic jacks. The assumption is that the masonry rings are a representative simplification of domes, especially their structural support. Both single layered domes and ribbed domes are exposed to tensile stress in up to one third of their height.

During the tests, the following information was collected: loads, displacements, strains of composites and failure modes. In some cases, an initial prestressing of reinforcements was carried out. Recommendations and limitations related to the use of the materials tested for reinforcing round, masonry structures under tensile stresses are discussed. The criterion for choosing the best solution was not only based on comparing the tensile strength of the reinforcement but also its stiffness. A strengthening efficiency index is proposed. The assessment of strengthening effectiveness was carried out, taking into account also heritage building conservation standards. Adopting the EF indicator as the criterion for assessing the effectiveness of reinforcement, it can be concluded that the application of the following methods should be considered in the structural maintenance of historical buildings: PBO mesh reinforcement in the PBO-FRCM system, carbon mesh reinforcement in the C-FRCM system and also basalt reinforcement in the B-FRCM system.
\end{abstract}

Keywords: Domes, Masonry, Strengthening, Composite materials, FRCM, CFRP

\section{Introduction}

Dome structures are to be found all over the world, and their symbolism has inspired many cultures. The great number of domes and their variety of form has encouraged many researchers to study domes from the point of view of architecture, construction, art, religion and philosophy. Today, many dome structures for many reasons require special attention from heritage building conservation and engineering design points of view.

Domes include the vaults and also the beam and shell structures, which converge at the highest point located above the center of gravity of the projection. In the case of brick and stone historical vaults, it is possible to

*Correspondence: piotr.frackiewicz@pwr.edu.pl

Department of Building Structures, Wrocław University of Science

and Technology, Wybrzeże Wyspiańskiego 27, 50-370 Wrocław, Poland distinguish rotary domes with a two-curved surface and polygonal domes made of interpenetrating cylindrical surfaces. From an engineering point of view, it is very significant that the geometrical arrangement of vault elements can be formulated in accordance with the theory of elasticity and plasticity. During static and strength analyses, spatial structures are often reduced to basic elements such as beams, columns or frames. Brick constructions with curved geometry are usually simplified to an arch, which can be treated as a representative element for describing the static work of the entire structure. For a certain group of building structures, a representative simplified element can be subjected to experimental testing, theoretical analyses and numerical simulations. A case in point is the strengthening ring under tensile load, which is subject to possible bending and shearing.

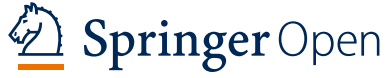

(c) The Author(s) 2021. This article is licensed under a Creative Commons Attribution 4.0 International License, which permits use, sharing adaptation, distribution and reproduction in any medium or format, as long as you give appropriate credit to the original author(s) and the source, provide a link to the Creative Commons licence, and indicate if changes were made. The images or other third party material in this article are included in the article's Creative Commons licence, unless indicated otherwise in a credit line to the material. If material is not included in the article's Creative Commons licence and your intended use is not permitted by statutory regulation or exceeds the permitted use, you will need to obtain permission directly from the copyright holder. To view a copy of this licence, visit http://creativeco mmons.org/licenses/by/4.0/. The Creative Commons Public Domain Dedication waiver (http://creativecommons.org/publicdomain/ zero/1.0/) applies to the data made available in this article, unless otherwise stated in a credit line to the data. 
For straightforward cases of spherical and polygonal domes, there are formal analytical solutions that, are easy to interpret when a membrane state of stress is assumed. This assumption is only valid when the stress state is torque-free, the thickness of the shell is small in relation to the other dimensions, and the central surface is continuously curved. In the membrane state, the normal stresses from axial forces and stresses tangential to the central surface occur. At this point, it can be stated unequivocally that in most domes, the static solution indicates the presence of tensile stress in the lower latitudinal bands regardless of their specific geometry. This stress state leads to the visible failure mode of domes as depicted in Fig. 1. A comprehensive summary of the static work of domes, with particular emphasis on the crack patterns on their behavior, can be found in [1].
The cracks occur in the bottom part of the dome and for simple static solution there is a possibility to determine the angle where tensile forces occur (Fig. 2).

The most problematic part of dome construction is the support zone. This is why the research program focused on examining this zone and proposing solutions to problems, which are also acceptable from a heritage conservation point of view. For this reason, the supporting zone research was simplified to focus on the masonry ring.

Traditional strengthening techniques, like reinforced concrete or steel elements, enable increased load capacity, rigidity and durability of the existing structure, but they are typically labor-intensive, often irreversible and questionable from an aesthetic point of view. To minimize the cross-sectional sizes of reinforcing materials, composites based on high-strength fibers, mainly carbon, aramid, glass, basalt and steel are used [4-6]. An important advantage of using composite materials is
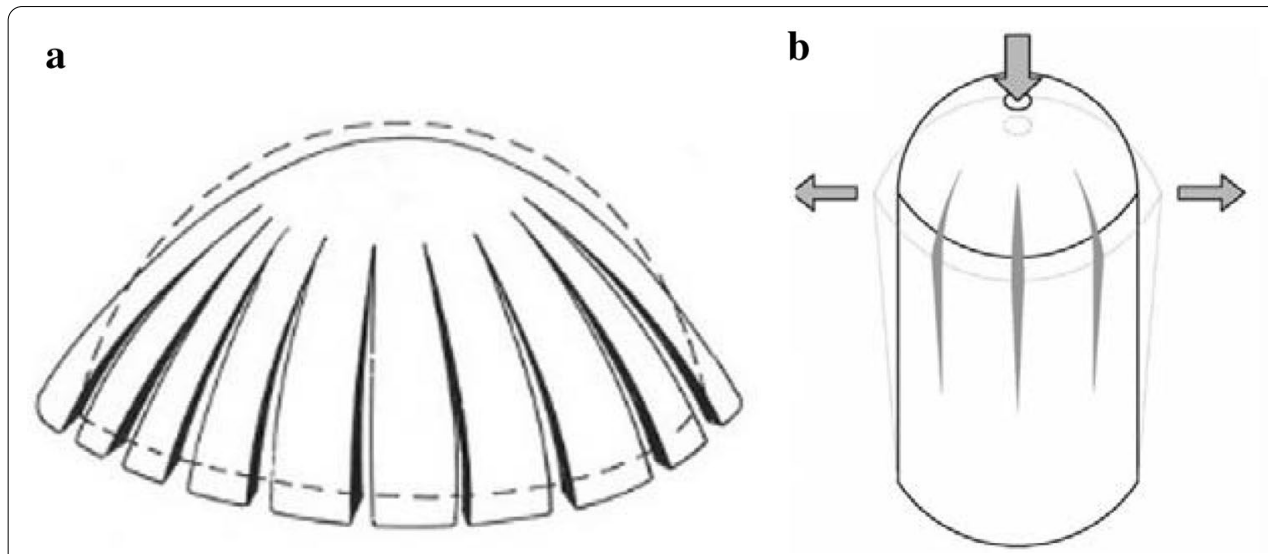

Fig. 1 The failure mode of domes: a separation of arches [1, 2] b vertical cracks [3]

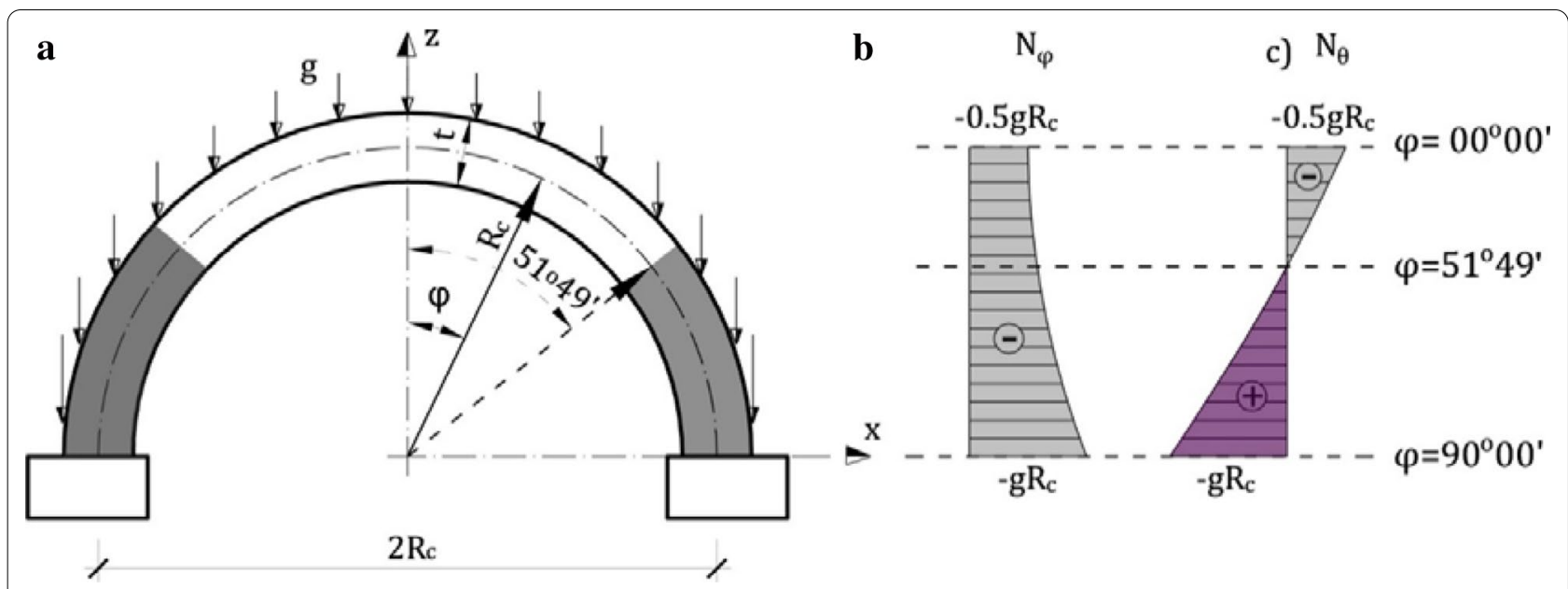

Fig. 2 The static solution for self-weight in the dome: a static scheme, $\mathbf{b}$ meridian forces, $\mathbf{c}$ parallel forces 
an undemanding adaptation to curved and rough surfaces. In the literature, there are numerous examples of reinforcements that have been applied to many different types of structural components, but examples of circumferential reinforcements of domes or cylindrical structures are relatively scarce, especially when it comes to reinforcements using composite materials. The procedures and methodology of the perimeter reinforcement of curved structures have largely been borrowed from the widely recognized issue of strengthening church towers in Europe. It is important that each historic object should be treated individually and each construction intervention should be preceded by an extensive research program. An appropriate approach to peripheral strengthening has been presented in [7-9]. A good example of the use of composites for the conservation of historic structures is the dome of the Bane Bashi Mosque $[10,11]$, where clamp strips and perimeter rods made of CFRP have been applied. The strengthening design was based on experience gained at a similar site-the Mustafa Pasha Mosque in Skopje and on the basis of this an analogous strengthening system was adopted. The dome's shell was reinforced using CFRP rings and arches, whereas the dome's support drum was strengthened with CFRP rods glued with epoxy resin. Research on the static behavior of the domes and cylindrical structures reinforced with composite materials is still ongoing, which may be the reason why their application in historical monuments is relatively scarce. An extensive research program focusing on the static behavior of masonry vaults and domes reinforced with CFRP tapes, preceded by extensive theoretical considerations, has been presented by Paolo Foraboschi, $[12,13]$. Therefore, further studies were conducted aimed at the effectiveness of bond between FRP and masonry, [14]. Another research program of note is the program implemented at Wrocław University of
Science and Technology in the Department of Building Structures, which is concerned with, inter alia, reinforcing brick arches with FRCM and CFRP systems [15]. In these cases, a load capacity increase of over $350 \%$ has been recorded. Due to numerous advantages, the application of composites and other modern materials is clearly increasing in the conservation of historic building structures. It should be mentioned here that another idea gaining importance for the strengthening of historic structures is the use of nanomaterials and nano-modified polymers, which enables the modification of the physical parameters of the original material without the addition of secondary strengthening elements, [16].

\section{Experimental research programme}

In domes and cylindrical structures, it is possible to distinguish in an experimental model, a latitudinal band in the form of a ring loaded from the inside.

The main goal of the research was to assess the effectiveness of peripheral strengthening using various techniques. For this purpose, 6 models (R1, R5, R6, R7, R8, and R9) of masonry rings were made, with loading applied from the inside by means of a dedicated hydraulic system. A complex stress state was induced using a 4-point loading scheme. Six different composite systems were used to strengthen the rings. The parameters of geometry, construction materials, loading system, and measuring instrumentation were the same for all six models. The methodology approach is presented below in form of a flowchart (Fig. 3). The methodology limitations are concentrated in the area of scale effect which regards the main dimensions of the ring. In the case of domes with a high value of diameter, the results of the test could be not appropriate.

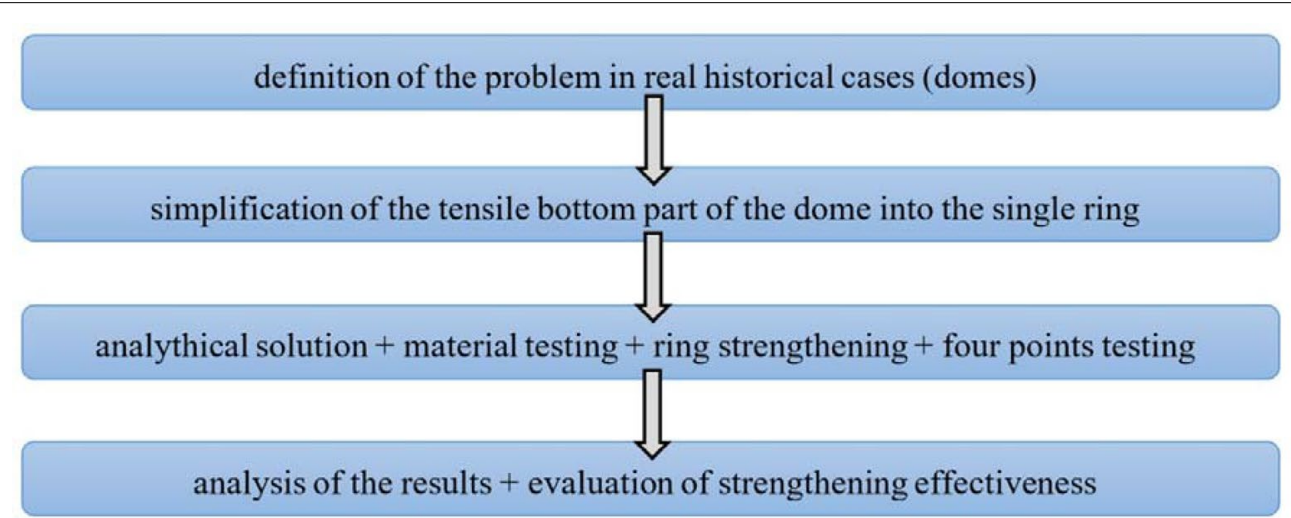

Fig. 3 The flowchart which presents methodology of research 


\section{Geometry and static scheme of the models}

An example of a model prepared for experimental testing is presented in Fig. 4. Critical dimensions, measuring instrumentation, and loading system are described below.

Models of masonry rings were built to a technical scale with geometrical parameters as detailed below.

Axial diameter of the ring: $\mathrm{d}=300 \mathrm{~cm}$,

Internal radius: $\mathrm{r}_{\mathrm{i}}=133.25 \mathrm{~cm}$,

Outer radius: $\mathrm{r}_{\mathrm{e}}=166.75 \mathrm{~cm}$,

Cross section: $A=250 \times 335 \mathrm{~mm}=83750 \mathrm{~mm}^{2}$,

Height: $\mathrm{h}=25 \mathrm{~cm}$.

The right brick bonds were selected to achieve maximum cross-sectional attachment and to minimize joint thickness. The joints between the bricks had a thickness in the range: $5 \div 20 \mathrm{~mm}$. Using appropriate brick elements, a repeatable bond was obtained. Thus the rings had 8 symmetrical axes. Stable temperature conditions prevailed in the laboratory hall during preparation and testing of the models with the air temperature in the range of $18 \div 22{ }^{\circ} \mathrm{C}$, and air humidity ranging between $45 \% \div 55 \%$.

The models were built on a base covered with PE foil to minimize the influence of friction. The friction coefficient of the brick substrate against the base had been calculated on the basis of a ramp test, yielding a value equal to $\mu=0.43$.

Figure 5 shows a diagram of the test stand, along with the arrangement of the sensors. The "F1" and "F2"

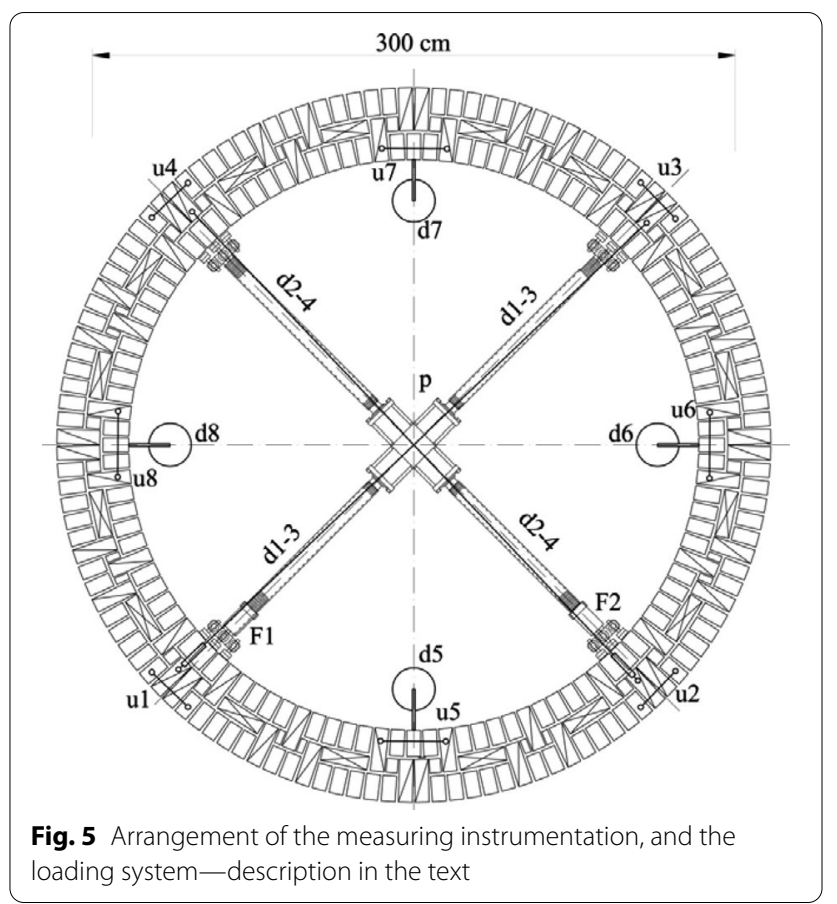

detectors are strain gauges which register pressure on the structure. "P" detectors registered pressure in the loading system. Additionally, a pressure gauge was installed at the hydraulic pump. Meters marked with the letter "d" were inductive displacement sensors (LVDT) recording the change in the diameter of the ring. The symbol " $\mathrm{u}$ "

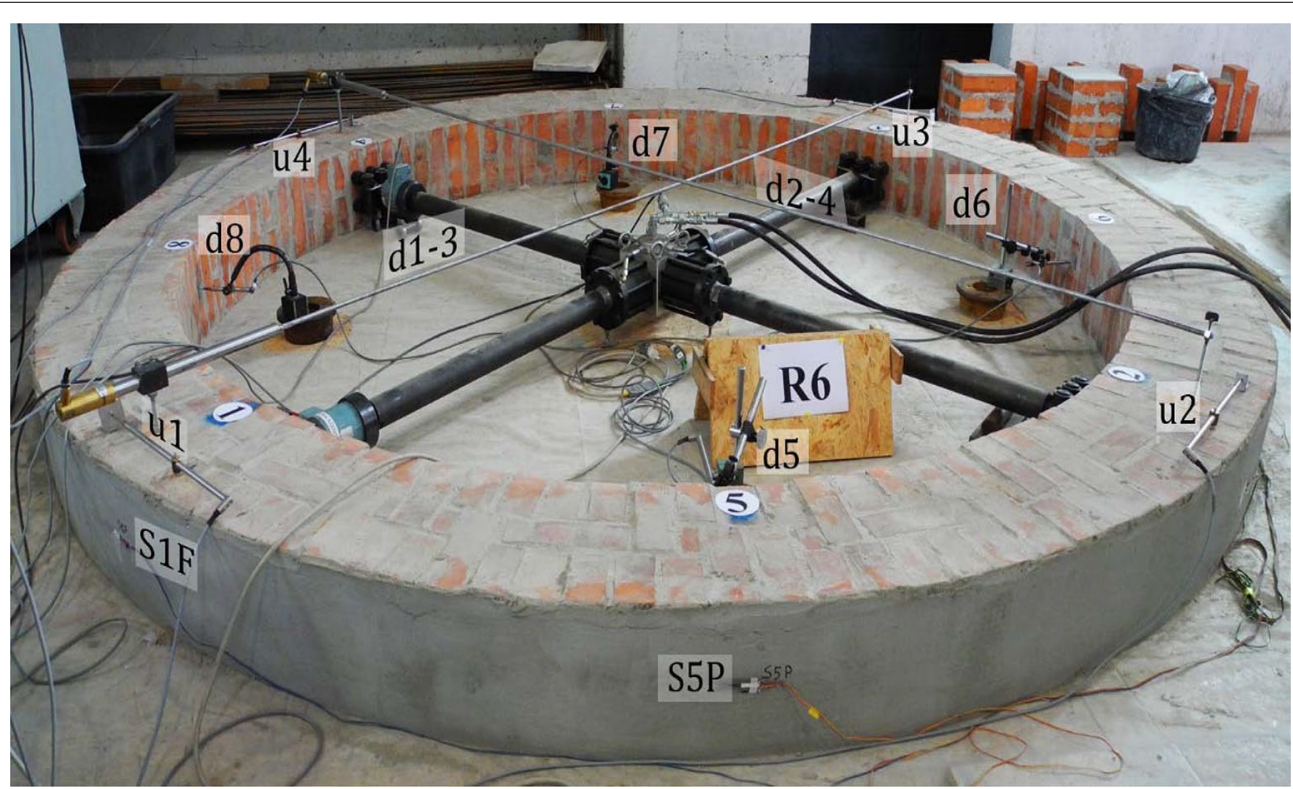

Fig. 4 Model R6 prepared for experimental testing 
denotes inductive displacement sensors (LVDT) recording displacements of the masonry structure points.

The design of the ring loading system was purposefully light and mobile. Its central part was made of a steel body composed of four double-acting hydraulic jacks with a stroke of $50 \mathrm{~mm}$ and a maximum working pressure of $20 \mathrm{MPa}$. The system ensured concentrated forces of 150 $\mathrm{kN}$ on each pressure unit were obtained and transmitted to the model through 6 elastomer discs.

The loading system transmitted force into four points (points 1, 2, 3, 4). Because of the device's limitations in the laboratory, there was no possibility to create 8 -point static scheme, which could better represent the real structures. This loading pattern resulted in a complex (unfavorable) stress state in the circumferential direction. The static solution of the ring (internal forces) is presented in Fig. 6. The resulting state of stress in the structure was designed to simulate the unfavorable forces occurring in the support zones of domes, which result from disturbances in support continuity (pendentives, pillars, columns).

\section{Bricks, mortar, and masonry properties}

One of the objectives of the research was to determine the material characteristics of the masonry, from which the rings models were made. This is why the bending and compression strength of the bricks and mortar was tested, and why the compression and shear strength of the masonry fragments was examined.

The compressive strength tests of the bricks were carried out in accordance with standard EN 772-1 [17]. The mean value was equal to $11.75 \mathrm{MPa}$, the standard deviation was $2.88 \mathrm{MPa}$ and a coefficient of variation was calculated at $24.5 \%$. A lime mortar with a grain size of $0 \div 2 \mathrm{~mm}$ was used in the construction of the models. The mortar was characterized by a high plasticity, $\mathbf{a}$

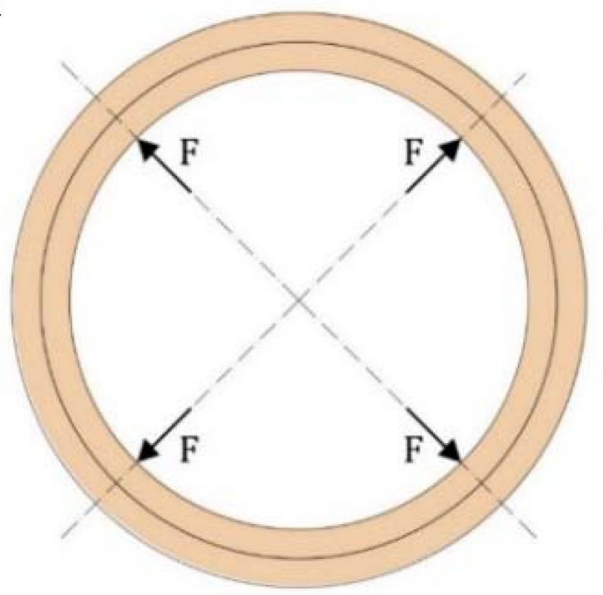

c

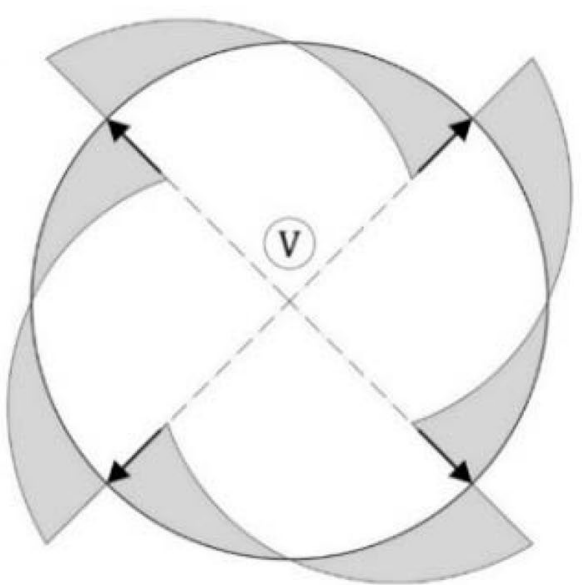

b

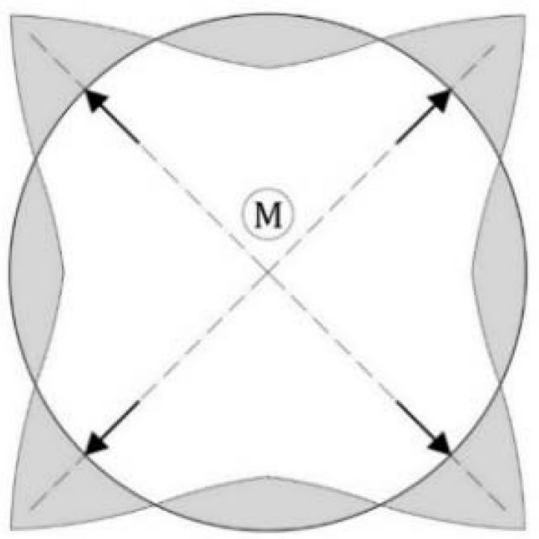

d

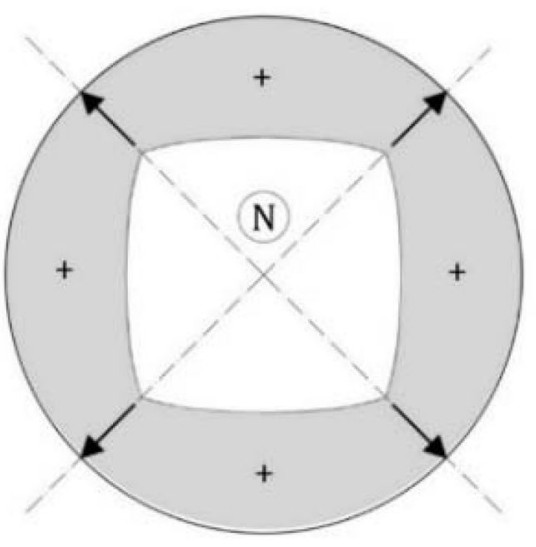

Fig. 6 The static solution of the ring, a static scheme $\mathbf{b}$ bending moments, $\mathbf{c}$ shear forces, $\mathbf{d}$ tensile forces 
low shrinkage (due to the longer setting time), and high adhesion to the substrate. These features are also characteristic of historical mortars. Bending and compression strength tests were carried out on 18 samples, 14, 21, and 28 days after forming, in accordance with the procedure described in EN 1015 standard, [18]. The average value for the compressive and shear strength of the lime mortar is similar to the results obtained in the testing of historical mortars by Matysek, [19] and Domasłowski et al. [20], which confirms the validity of its use in reconstructions and experimental testing of historic structures.

In addition to tests of individual materials, an examination was carried out of the entire structure of masonry elements. The value of the average compressive strength of the brickwork was converted into a characteristic value and then compared to the characteristic value calculated according to the Eurocode formula (taking into account specific parts of the masonry), [21]. The experimental value was found to be more than three times higher. Table 1 summarizes the key results of all the tests conducted.

\section{Table 1 Mechanical properties of bricks, mortar, and masonry}

Brick compressive strength

Mortar compressive strength

Mortar tensile strength

Compressive strength

Young's modulus

Plastic deformation (under compression)

Limit deformation (under compression)

Shear strength

$$
\begin{array}{r}
f_{c, b}=11.75 \mathrm{MPa} \\
f_{c, m}=5.76 \mathrm{MPa} \\
f_{x, m}=1.34 \mathrm{MPa} \\
f_{c}=15.47 \mathrm{MPa} \\
E=2.21 \mathrm{GPa} \\
\varepsilon_{c, p l}=0.70 \% \\
\varepsilon_{c, \text { max }}=0.94 \% \\
f_{V}=0.121 \mathrm{MPa}
\end{array}
$$

\section{Strengthening methods}

The following systems were used to strengthen the rings:

R1: Single CFRP strip attached to the masonry by a two-component epoxy composition;

R5: Single-layered carbon fiber wrap on epoxy resin;

R6: Two layers of glass fiber mesh embedded in a mineral matrix;

R7: Four layers of B-FRCM system based on basalt fiber mesh embedded in a mineral matrix;

R8: Three layers of carbon fiber mesh embedded in a mineral matrix;

R9: Three layers of P.B.O. fiber mesh embedded in a mineral matrix.

Figure 7 shows all the reinforcing materials used. Most of them were covered additionally with a top layer of the matrix. Table 2 summarizes the mechanical properties of the reinforcing materials. The data are based on the technical sheets of individual products. where: $\mathrm{e}$-the number of reinforcing elements at the height of the ring, $A_{r e}=e \cdot A_{r}$-total cross-sectional area of the reinforcement, $\mathrm{K}_{\mathrm{EA}}=\mathrm{E} \cdot \mathrm{A}_{\mathrm{re}}$-stiffness of the reinforcement during tension, $R_{u}=f_{u} \cdot A_{r e}$-tensile strength capacity of the reinforcement.

It is worth to underline that methods that consist of fibers in the mineral matrix (FRCM system) are more suitable for historical constructions because of the higher diffusion coefficient in comparison with FRP systems which consist of fibers in the polymer matrix. Furthermore, the advantages of FRCM systems are higher fire resistance and better reversibility.

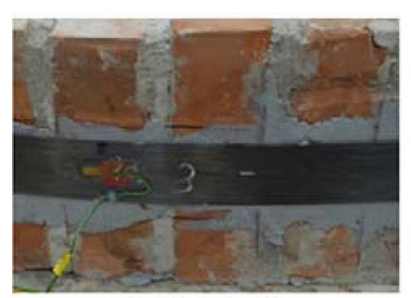

R1 CFRP strips

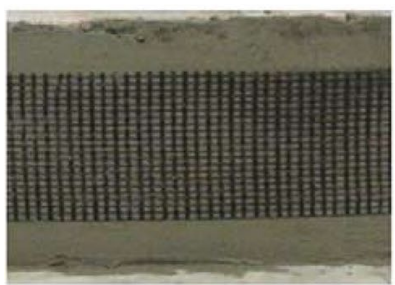

R7 B-FRCM mesh

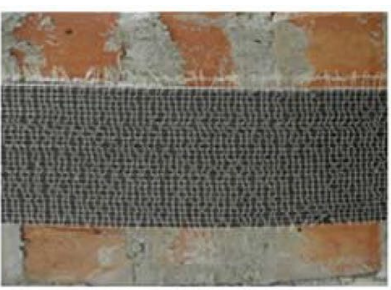

R5 CFRP wrap

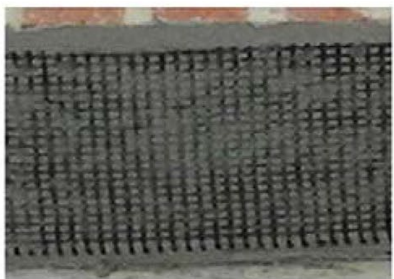

R8 C-FRCM mesh

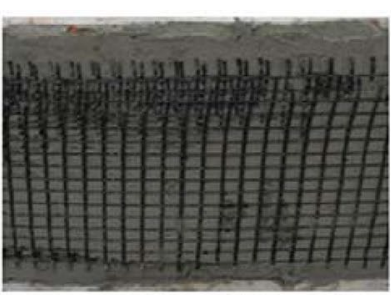

R6 G-FRCM mesh

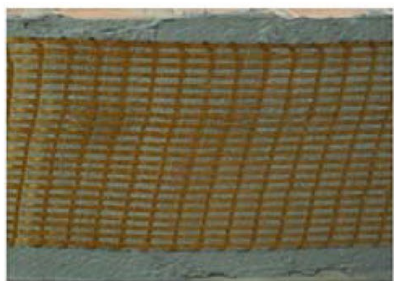

R9 PBO-FRCM mesh

Fig. 7 Types of strengthening used in research programme 
Table 2 Values of compressive and shear strength for masonry elements

\begin{tabular}{|c|c|c|c|c|c|c|c|c|}
\hline Model & Material & Cross- section [mm] & $e[-]$ & $A_{r e}\left[\mathrm{~mm}^{2}\right]$ & $E[\mathrm{GPa}]$ & $K_{E A}[\mathrm{MN}]$ & $f_{u}[\mathrm{MPa}]$ & $R_{u}[\mathrm{kN}]$ \\
\hline R1 & CFRP strips & $1.4 \times 60$ & 1 & 84.0 & 170 & 14.28 & 2600 & 218.4 \\
\hline R5 & Carbon fiber fabric & $0.440 \times 120$ & 1 & 52.8 & 242 & 12.78 & 3800 & 200.6 \\
\hline R6 & Glass fibers net & $0.024 \times 200$ & 2 & 9.6 & 72 & 0.69 & 1250 & 12.0 \\
\hline R7 & Basalt fibers net & $0.039 \times 150$ & 4 & 23.6 & 89 & 2.10 & 1538 & 36.3 \\
\hline R8 & Carbon fiber net & $0.047 \times 200$ & 3 & 28.2 & 103 & 2.90 & 1031 & 29.1 \\
\hline R9 & P.B.O fiber net & $0.046 \times 200$ & 3 & 27.6 & 95 & 2.62 & 1664 & 45.9 \\
\hline
\end{tabular}

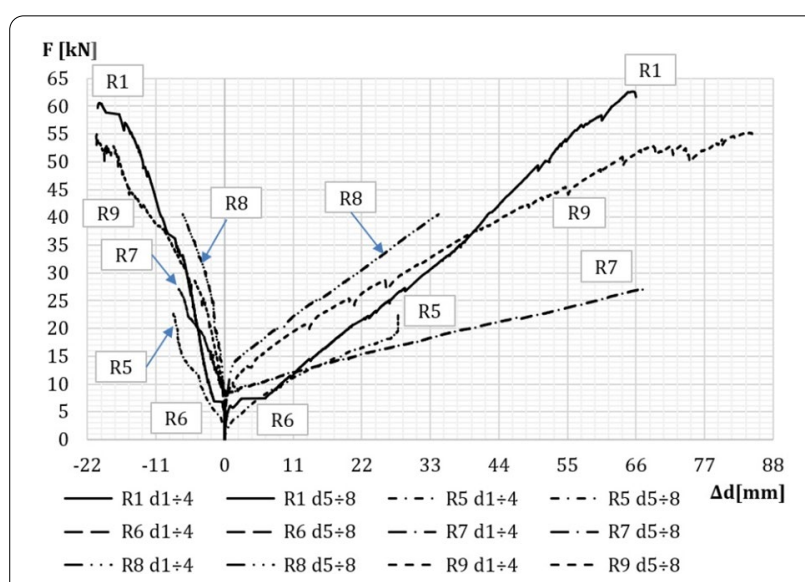

Fig. 8 Comparison of ring test results: force displacement relation

\section{Results and discussion}

The results of the experimental testing are presented in relation to three different aspects and in the form of synthesis.

\section{Force-displacement relation}

Ring deformation analysis (Fig. 8) shows that the R1 and R8 models had the greatest stiffness, whereas a slightly worse result was obtained for the R9 model. The lowest rigidity was demonstrated by the R6 model, which was confirmed by the lowest $\mathrm{K}_{\mathrm{EA}}$ value. The values obtained for the R5 and R7 models were in-between the extremes, which in the case of the $\mathrm{R} 5$ ring is surprising. This could be explained by the strengthening technology used and the possibility of slip between the mat and epoxy resin.

\section{Load carrying capacity}

Due to the diversity of reinforcing materials used, the stiffness of strengthening materials under axial tension $\mathrm{K}_{\mathrm{EA}}$ and the tensile strength $\mathrm{R}_{\mathrm{u}}$ were adopted as the parameters for comparative analysis. The highest tensile strength was recorded for the carbon fiber strip (used in the R1 model) and the CFRP wrap (used in the
R5 model), and the lowest load capacity was recorded for the double glass mesh in the G-FRCM system (used in the $\mathrm{R} 6$ model). In this phase of research, the rings were loaded right up to their destruction. A comparison of the maximum values of destructive forces provides an estimate of the effectiveness of the reinforcement system used in relation to increasing the load capacity after reinforcement (Fig. 9).

As expected, the highest load capacity was obtained in the R1 model reinforced with carbon fiber strip, and the lowest in the case of the R6 model reinforced with glass fibers mesh. The result achieved using PBOFRCM nets should be noted.

There were also observed following, main failure modes:

- Masonry crushing: R1 and R9

- Reinforcement rupture: R5, R6, R7, R8

\section{Assessment of strengthening effectiveness}

According to conservation doctrines, strengthening historical objects should strive to achieve the intended strengthening effects with the smallest possible crosssection of added elements. For this reason, a quantitative assessment of reinforcement effectiveness was carried out as part of the comparative analysis of the experimental results obtained from all the ring models. This involved calculating the EF factor, which is the quotient of the ultimate force for the ring after reinforcement $\mathrm{F}_{\max }[\mathrm{N}]$ and the stiffness of the reinforcing materials under tensile strength $\mathrm{K}_{\mathrm{EA}}[\mathrm{N}]$ :

$$
E F=\frac{F_{\max }}{K_{E A}}
$$

Based on the calculations of the EF factor (1), it can be concluded that reinforcements using FRCM systems are the most beneficial, especially P.B.O fiber nets (Table 3). The R1 model revealed the best stiffness and the highest carrying load capacity. 


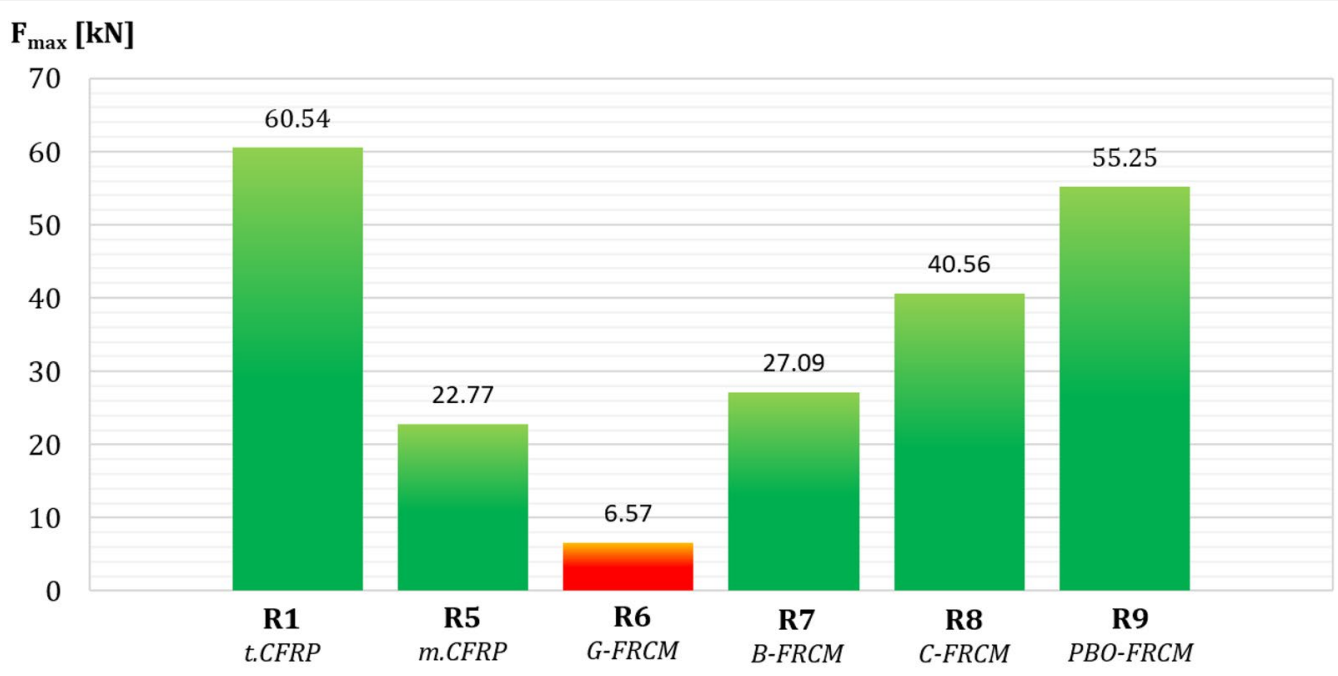

Fig. 9 Comparison of load bearing capacity of strengthened ring models

Table 3 Comparison of strengthening effectiveness

\begin{tabular}{lccllll}
\hline Ring coefficient & R1 & R5 & R6 & R7 & R8 & R9 \\
\hline EF factor & 4.2 & 1.8 & 9.5 & 12.9 & 14.0 & 21.1 \\
Destructive force $[\mathrm{MPa}]$ & 60.54 & 22.77 & 6.57 & 27.09 & 40.56 & 55.25 \\
\hline
\end{tabular}

\section{Conclusions}

It is possible to create a complex, unfavorable stress state which simulates the forces occurring in the bases of domes using the loading system for the ring as proposed in this paper. It is very difficult to find a similar research program, where masonry rings are tested. That is why there is no possibility to compare the results with other scientific investigations. The use of contemporary materials (bricks, mortars) to create models simulating historical structures is possible, provided that their parameters are strictly controlled.

Based on the results obtained from experimental testing of the rings, it is possible to estimate the increase in the load capacity of the structure after reinforcement, which in turn allows the number of reinforcing elements to be minimized while ensuring maximum diffusion surface and minimal interference with the historical substance.

The R1 ring, which was reinforced with a single CFRP strip, recorded the greatest load capacity. The weakest reinforcement was recorded for the double glass fiber mesh in the FRCM system-model R6. Adopting the EF indicator as to the criterion for assessing the effectiveness of reinforcement, it can be concluded that the application of the following methods should be considered in the structural maintenance of historical buildings: $\mathrm{PBO}$ mesh reinforcement in the PBO-FRCM system $(E F=21.1)$, carbon mesh reinforcement in the C-FRCM system $(E F=14.0)$ and also basalt reinforcement in the B-FRCM system $(\mathrm{EF}=9.5)$.

In future research programs similar to those presented in the paper, the scale effect should be taken into account and another strengthening technique (like carbon or aramid fibers in form of single ropes arranged on the ring height) should be included.

\section{Abbreviations}

CFRP: Carbon Fiber Reinforced Polymer (Plastics) B; PBO: Poliparafenilenbenzobisoxazol; FRCM: Fiber Reinforced Cementitious Matrix; LVDT: Linear variable differential transformer; EF: Effective Factor for strengthening technique.

\section{Acknowledgments}

These experiments were performed at the Wroctaw University of Science and Technology in the Department of Building Structures.

\section{Authors' contributions}

JJ Research concept, main assumptions. KR Principal investigator, analysis of the results. PF Analysis and development of results and editing. KK State of art summary and editing. $Ł B$ consultation and selection of instrumentation. All authors read and approved the final manuscript.

\section{Funding}

The Department of Building Structures of Wrocław University of Science and Technology has supported this research. 


\section{Availability of data and materials}

The datasets used and analyzed during the current study are available from the corresponding author on reasonable request. The materials are described in experimental sections.

\section{Competing interests}

The authors declare that they have no competing interests.

Received: 20 October 2020 Accepted: 16 January 2021

Published online: 27 January 2021

\section{References}

1. Foraboschi P. The central role played by structural design in enabling the construction of buildings that advanced and revolutionized architecture. Constr Build Mater. 2016;114(July):956-76.

2. Varma M. N, Jangid R S, Achwal V G. Tension Ring in Masonry Domes. New Delhi: International Conference on Structural Analysis of Historical Constructions; 2006

3. Blasi C, Ottoni F, Lupone I, Tesi V. On the hooping of large masonry domes: discussion on strain measurements and interaction with masonry. 9th International Conference on Structural Analysis of Historical Constructions, F.Pena, M.Chavex, Mexico City. Mexico, 14-17 October 2014

4. Jasieńko J, Raszczuk K, Moczko M, Piechówka - Mielnik M. Selected aspects of the structural analysis of the north dome in the "Four Domes Pavilion. Civil and Environmental Engineering Report. 2015; 17(2): 33-41

5. Hemeda S. 3D finite element coupled analysis model for geotechnical and complex structural problems of historic masonry structures: conservation of Abu Serga church, Cairo, Egypt. Heritage Science; 2019, 7(1), 6

6. Jasieńko J, Raszczuk K, Wójcik D, Misztal W. Application of cords in the structural conservation of historic buildings. J Heritage Conservation. 2018;53:124-36.

7. Ferraioli M, Lavino A, Abruzzese D, Avossa AM. Seismic assessment, repair and strengthening of a medieval masonry tower in southern Italy. Int J Civil Engineering. 2020;18(9):967-94.

8. Modena C, Valluzzi MR, Tongini Folli R, Binda L. Design choices and intervention techniques for repairing and strengthening of the Monza cathedral bell-tower. Constr Build Mater. 2002;16(7):385-95.
9. Mason JA. Strengthening of a historic unreinforced masonry church tower. Practice Periodical on Structural Design and Construction. 2008:13(1):31-8.

10. Milev Y, Milev N. Retrofit of damaged by the Earthquake in Sofia 2012 Bane Bashi Mosque. Proceedings of the 2nd International Conference on Protection of Historical Construction. Bogazci University Publishing, editors: Mazzolani, F.M, Altay G. Istanbul, 2014

11. Lazarov L, Todorov K. New strengthening approach of Mustafa Pasha Mosque to seismic loading. Protection of Historical Buildings. Prohitech 09-Mazzolani (ed). London: Taylor\&Francis Group; 2009, 125-130

12. Blasi P, Foraboschi P. Analytical approach to collapse mechanisms of circular masonry arch. Journal of Structural Engineering - ASCE (United States). 1994; 120(8): 2288-2309.

13. Foraboschi P. Strengthening of Masonry Arches with Fiber - Reinforced Polymer Strips. J Composites Construction. 2004;8(3):191-202.

14. Foraboschi P. Effectiveness of novel methods to increase the FRP masonry bond capacity. Compos B Eng. 2016;107(December):214-32.

15. Jasieńko J, Bednarz Ł. Strengthening of historic masonry vaults. International Masonry Conference. Dresden, 2010

16. Hemeda S, Khalil M, Shoeb A, El Aziz AA. The effectiveness of nano materials and nano-modified polymers for preservation of historic brick masonry in Rashid. Egypt Int J Conservation Sci. 2018;9(4):835-46.

17. EN 772-1:2001. Methods of test for masonry units - Part 1: Determination of compressive strength.

18. EN 1015-11:2019. Methods of test for mortar for masonry - Part 11: Determination of flexural and compressive strength of hardened mortar.

19. Matysek P. Identyfikacja wytrzymałości na ściskanie i odkształcalności murów ceglanych w obiektach istniejących. Kraków: Politechnika Krakowska; 2014. (in Polish).

20. Domasłowski W, Kęsy-Lewandowska M, Łukaszewicz J. Badania nad konserwacją murów ceglanych. Toruń: Uniwersytet Mikołaja Kopernika w Toruniu; 2004. (in Polish).

21. EN 1996-1-1. Eurocode 6 - Design of masonry structures - Part 1-1: General rules for reinforced and unreinforced masonry structures.

\section{Publisher's Note}

Springer Nature remains neutral with regard to jurisdictional claims in published maps and institutional affiliations.

\section{Submit your manuscript to a SpringerOpen ${ }^{\circ}$ journal and benefit from:}

- Convenient online submission

- Rigorous peer review

- Open access: articles freely available online

High visibility within the field

- Retaining the copyright to your article

Submit your next manuscript at $\boldsymbol{\nabla}$ springeropen.com 